\title{
Produtividade e eficiência de produção de vacas de diferentes grupos genéticos submetidas a pastagens cultivadas no pré ou pós-parto
}

\section{Productivity and production efficiency of cows of different genetic groups submitted to cultivated pastures during pre or postpartum}

\author{
Ricardo Zambarda Vaz ${ }^{1 *}$; João Restle ${ }^{2}$; Paulo Santana Pacheco ${ }^{3}$; \\ Fabiano Nunes Vaz ${ }^{3}$; Dari Celestino Alves Filho ${ }^{3}$; Ivan Luiz Brondani³; \\ Leonir Luiz Pascoal ${ }^{3}$; Flânia Mônego Argenta ${ }^{4}$
}

Resumo

\begin{abstract}
Avaliou-se através do desenvolvimento de vacas e bezerros até o desmame aos 90 dias e também do desempenho reprodutivo desde a prenhez até a desmama, a produtividade e a eficiência de 94 vacas de corte dos grupos genéticos Charolês $(\mathrm{CH})$, Nelore (NE), 1/2 $\mathrm{CH}$ 1/2 $\mathrm{NE}$ e 1/2 $\mathrm{NE} 1 / 2 \mathrm{CH}$ submetidas aos seguintes sistemas de alimentação: vacas mantidas exclusivamente em pastagem nativa (PN); vacas mantidas em pastagem cultivada (PC), composta por aveia (Avena sativa), azevém (Lollium multiflorum) e trevo vesiculoso (Trifolium vesiculosum) durante o período de 15 de julho a 15 de setembro e o restante do período experimental em pastagem natural $(\mathrm{PCN})$; e vacas mantidas em pastagem cultivada durante o período de 15 de setembro a 15 de novembro, e o restante do período em pastagem nativa (PNC). As vacas mantida em PC produziram $22,6 \%$ a mais de bezerros do que as vacas mantidas exclusivamente em PN, bem como foram mais eficientes no índice de produção de bezerros (eficiência dos rebanhos), com 57,0 vs $37,0 \mathrm{~kg}$ de bezerros/vaca mantida no rebanho. Na produção de $\mathrm{kg}$ de bezerros por vaca, as fêmeas mantidas em $\mathrm{PC}$ no pós-parto $(69 \mathrm{~kg})$ foram superiores $(\mathrm{P}<0,05)$ as mantidas em pastagem cultivadas no pré-parto $(61 \mathrm{~kg})$ e estas superiores as mantidas exclusivamente em PN (53 kg). Entre as vacas puras, as Charolês foram mais produtivas com maior índice de produção de bezerros necessitando de menos vacas para a produção de um bezerro. Entre as vacas cruzadas não ocorreu diferença nas variáveis estudas $(\mathrm{P}>0,05)$, sendo estas superiores as puras na produtividade e eficiência produtiva.

Palavras-chave: Charolês, cruzamento, ganho de peso, índice de produção de bezerros, Nelore, taxa de desmama
\end{abstract}

\footnotetext{
Abstract

We assessed through the weight of cows and calves up to weaning at 90 days and the reproductive performance from pregnancy to weaning, the productivity and efficiency of 94 Charolais $(\mathrm{CH})$, Nellore (NE), $1 / 2 \mathrm{CH} 1 / 2 \mathrm{NE}$ e $1 / 2 \mathrm{NE} 1 / 2 \mathrm{CH}$ cows submitted the following feeding systems: cows kept on native pasture (NP); cows kept on cultivated pasture (CP), composed of oat (Avena sativa), ryegrass (Lollium multiflorum) and clover (Trifolium vesiculosum) from July 15 to September 15 and the remainder of the trial on natural pasture (CPN); and cows kept on cultivated pasture during September 15 to November 15 , and the remainder on native pasture (NPC). Cows kept on CP produced $22.6 \%$ more calves than

${ }^{1}$ Prof. Adjunto, Universidade Federal de Pelotas, UFPEL, Pelotas, RS. E-mail: rzvaz@terra.com.br

${ }^{2}$ Prof. Visitante Nacional Sênior, Universidade Federal do Tocantins, UFT, Araguaína, TO. E-mail: jorestle@terra.com.br

${ }^{3}$ Profs. Adjuntos, Universidade Federal de Santa Maria, UFSM, Santa Maria, RS. E-mail: paulosantanapacheco@hotmail.com; fabianonunesvaz@gmail.com; darialvesfilho@hotmail.com; ivanbrondani@gmail.com; 1lpascoal@yahoo.com.br

${ }^{4}$ Discente do PPG em Zootecnia, UFSM, Santa Maria, RS. E-mail: flaniama@yahoo.com.br
}

* Autor para correspondência 
cows kept exclusively on NP, and were more efficient $(\mathrm{P}<.05)$ for calf production index (efficiency of herds) with $57 \mathrm{vs} 37 \mathrm{~kg}$ of calves/cow kept in the herd. For the production of $\mathrm{kg}$ of calves per cow, cows kept postpartum on $\mathrm{CP}(69 \mathrm{~kg})$ were higher $(\mathrm{P}<0.05)$ to those kept on the cultivated pasture during antepartum $(61 \mathrm{~kg})$ and both superior to cows maintained exclusively on NP $(53 \mathrm{~kg})$. Between purebred cows the Charolais were more productive with higher index production of calves requiring less cows for the production of one calf. Between crossbred cows there was no difference in the variables studied $(\mathrm{P}>.05)$, being higher than the purebreds in productivity and production efficiency.

Key words: Charolais, crossbreeding, calf production index, Nellore, weaning rate, weight gain

\section{Introdução}

A eficiência produtiva dos rebanhos de cria tem importância significativa nos indicadores de produtividade (BERETTA; LOBATO; MIELITZ NETO, 2002). A eficiência produtiva, na fase de cria, é uma associação entre o desempenho reprodutivo e a habilidade materna das vacas e a conversão da produção do leite em ganho de peso dos bezerros (RESTLE; HARGROVE; KOGER, 1984; RIBEIRO et al., 2001; VAZ; LOBATO; RESTLE, 2010).

$\mathrm{O}$ aumento da produtividade dos sistemas de cria pode ser alcançado através do uso de tecnologias buscando a melhoria das condições para as vacas ao longo do ano (VIEIRA et al., 2005a). Dentre as tecnologias pode-se citar o ajuste de carga animal (FAGUNDES; LOBATO; SCHENKEL, 2003) a utilização de suplementação alimentar para o rebanho (CERDÓTES et al., 2004; MULLER et al., 2010) ou de pastagens cultivadas (LOBATO et al., 1998) ou ainda a utilização do desmame precoce (VAZ; LOBATO; RESTLE, 2010).

Dentre as fases de cria, o terço final da gestação seguida da lactação são as fases nas quais os requerimentos nutricionais das vacas aumentam consideravelmente (NRC, 1996), e as pastagens naturais não conseguem suprir as exigências dos animais (RESTLE et al., 2001), afetando o desempenho do rebanho de cria (ROVIRA, 1974; VIEIRA et al., 2005a).

A utilização de pastagens cultivadas no pré e pós-parto para os rebanhos de cria visa proporcionar às vacas, melhores condições alimentares e, consequentemente, maiores ganhos de pesos e condições corporais resultando em melhor desempenho reprodutivo, bem como maior produção de leite refletido no desenvolvimento dos bezerros. O empecilho da utilização de tecnologias para alavancar os índices produtivos dos rebanhos de cria é o custo das mesmas, mas também a sua má avaliação dentro do sistema produtivo (VAZ; LOBATO; RESTLE, 2010).

Diversas medidas de eficiência produtiva podem ser encontradas na literatura (RESTLE; HARGROVE; KOGER, 1984; EUCLIDES FILHO; FIGUEIREDO; EUCLIDES, 1995; RIBEIRO et al., 2001). Além destas características, devem ser associados dados de desempenho reprodutivo às medidas de eficiência produtiva para melhor avaliação e entendimento da produtividade dos rebanhos (EUCLIDES FILHO; FIGUEIREDO; EUCLIDES, 1995; BARCELLOS; LOBATO; FRIES, 1996; VAZ; LOBATO; RESTLE, 2010).

O presente estudo objetivou avaliar no pré e pósparto, o uso de pastagens cultivadas de inverno e seus reflexos na produção e eficiência de produção de vacas de diferentes grupos genéticos e de diferentes idades.

\section{Material e Métodos}

$\mathrm{O}$ experimento foi conduzido no Setor de Bovinocultura de Corte do Departamento de Zootecnia da Universidade Federal de Santa Maria, em Santa Maria - RS, localizado na Depressão Central, a $153 \mathrm{~m}$ de altitude, que, segundo classificação de Köppen, apresenta clima subtropical úmido (cfa) (MORENO, 1961). 
Foram utilizadas 94 vacas do rebanho experimental com idade de três a dez anos, dos grupos genéticos Charolês $(\mathrm{CH})$, Nelore $(\mathrm{NE})$, $1 / 2 \mathrm{CH} 1 / 2 \mathrm{NE}$ e $1 / 2 \mathrm{NE} 1 / 2 \mathrm{CH}$. O período de parição foi de 15 de setembro a 15 de dezembro. Os bezerros foram obtidos de inseminação artificial (período de 45 dias) e de monta natural (período de 45 dias), utilizando-se, para inseminação, o sêmen de oito touros $\mathrm{CH}$ e $\mathrm{NE}$ e, para o repasse, dois touros $\mathrm{CH}$ e dois NE.

No momento do parto as vacas foram distribuídas segundo os seus grupos genéticos e suas idades, de forma que todos os tratamentos tivessem o mesmo número de animais de todos os grupos genéticos e idades. Os animais foram submetidos aos seguintes sistemas de alimentação: vacas mantidas exclusivamente em pastagem nativa; vacas mantidas em pastagem cultivada, composta por aveia (Avena sativa), azevém (Lollium multiflorum) e trevo vesiculoso (Trifolium vesiculosum) durante o período de 15 de julho a 15 de setembro e o restante do período experimental em pastagem nativa; e vacas mantidas em pastagem cultivada composta por aveia, azevém e trevo vesiculoso durante o período de 15 de setembro a 15 de novembro, e o restante do período em pastagem natural.

Para os animais mantidos em pastagem cultivada utilizou-se uma área de 18,2 ha, sendo que a implantação do trevo vesiculoso ocorreu no ano anterior, enquanto que a aveia e o azevém foram implantados em plantio direto, utilizando-se $80 \mathrm{~kg}$ de semente de aveia e $25 \mathrm{~kg}$ de semente de azevém/ ha, sendo a adubação realizada de acordo com a avaliação e recomendação das análises de solo. Para os animais mantidos em pastagens naturais foi utilizada uma área de 90,4 ha. As cargas animais foram de 864 e de $360 \mathrm{~kg} /$ ha para pastagem cultivada e pastagem natural, respectivamente.

As vacas dos diferentes grupos genéticos e grupos de idades quando lotadas em campo nativo ou na pastagem cultivada foram manejadas sempre em um grupo único. Até o momento do desmame dos bezerros que ocorreram durante os meses de dezembro a fevereiro e realizados em etapas, à medida que os animais alcançavam a idade de 90 dias, permaneceram com suas mães em pastagens natural ou cultivada, conforme os tratamentos previamente estipulados.

No início do período de parição foram colocados junto às vacas, rufiões com bucal marcador para auxiliar na identificação dos estros nas vacas. O período reprodutivo subsequente foi de 01 de dezembro até 28 de fevereiro, perfazendo 90 dias. O método reprodutivo utilizado foi inseminação artificial com duas recorridas diárias para a observação do estro, sendo uma de manhã e outra à tarde. As vacas que manifestavam estro pela manhã eram inseminadas à tarde, e as que manifestavam estro à tarde eram inseminadas na manhã do dia seguinte. $\mathrm{O}$ diagnóstico de prenhez foi avaliado 60 dias após o término do período de acasalamento através de palpação retal.

Para a produtividade do rebanho e eficiência das vacas em reprodução foram considerados os ganhos totais de pesos das vacas e bezerros $(\mathrm{kg})$ desde o parto até o desmame. Também foi determinada a eficiência de produção de bezerros através do índice de produção de bezerros, ajustado de acordo com a taxa de prenhez em $\mathrm{kg}$ de bezerros desmamados por vaca mantida (peso dos bezerros ao desmame * taxa de prenhez /100), kg de bezerro desmamado por $100 \mathrm{~kg}$ de tamanho metabólico da vaca ao desmame ( $\mathrm{kg}$ desmamado/100 $\mathrm{kg} \mathrm{vaca}{ }^{0,75}$ ).

Para a produtividade do rebanho e eficiência das vacas em reprodução foram considerados quilos de bezerros desmamados por vaca e quilos de bezerros desmamados para cada $100 \mathrm{~kg}$ de peso vivo da vaca. Os cálculos desses parâmetros foram realizados em função do número de vacas expostas à reprodução na estação de monta e do número de bezerros vivos à idade do desmame. Foi utilizado o peso médio das vacas ao início do período reprodutivo.

Para as medidas de eficiência dos rebanhos foram utilizados os resultados de desempenho 
reprodutivos (Tabela 1; SENNA, 1996), $\mathrm{Na}$ avaliação das taxas de perdas reprodutivas, compreendendo desde a taxa de manifestação foram consideradas as mortalidades ocorridas de estros e prenhez até a taxa de natalidade na estação de parição subsequente, obtidas em relação ao número total de fêmeas acasaladas. entre a manifestação de estro e o diagnóstico de gestação e deste ao nascimento dos bezerros no ano subsequente.

Tabela 1. Desempenho reprodutivo desde a manifestação de cios até a parição de vacas de cortes mantidas em diferentes sistemas alimentares

\begin{tabular}{lccc}
\hline & \multicolumn{3}{c}{ Sistemas de alimentação } \\
\cline { 2 - 4 } & Pastagem natural & $\begin{array}{c}\text { Pastagem cultivada + Pastagem } \\
\text { natural }\end{array}$ & $\begin{array}{c}\text { Pastagem natural + Pastagem } \\
\text { cultivada }\end{array}$ \\
\hline Estros, \% & $67,0^{\mathrm{B}}$ & $82,0^{\mathrm{A}}$ & $75,0^{\mathrm{A}}$ \\
Prenhez, \% & $57,0^{\mathrm{A}}$ & $65,0^{\mathrm{A}}$ & $56,0^{\mathrm{A}}$ \\
Parição, $\%$ & $43,8^{\mathrm{B}}$ & $62,5^{\mathrm{A}}$ & $53,1^{\mathrm{A}}$ \\
\hline
\end{tabular}

A,B Na mesma linha diferem $(\mathrm{P}<0,05)$ pelo teste de qui-quadrado.

Fonte: (SENNA, 1996).

O delineamento experimental foi o inteiramente casualizado em arranjo fatorial $3 \times 4$ (três sistemas alimentares $\mathrm{x}$ quatro grupos genéticos de vacas). Os resultados foram submetidos à análise de variância e ao teste F. O modelo matemático utilizado para as análises foi:

$$
\Psi i j k l=\mu+\mathrm{IV} i+\mathrm{PAST} j+\mathrm{SAV} k+\mathrm{GGV} l(\mathrm{SAV})
$$
$k+\left(\mathrm{PAST}^{*} \mathrm{GGV}[\mathrm{SAV}]\right) j k l+(\mathrm{PAST} * \mathrm{SAV}) j k+\varepsilon i j k l$, em que:

$\Psi i j k l=$ variáveis dependentes; $\mu=$ média geral de todas as observações; IV $i=$ efeito da covariável idade da vaca de ordem "i"; PAST $j=$ efeito do sistema de alimentação de ordem “j”, em que $1=$ pastagem natural $\mathrm{PN} ; 2$ = pastagem natural mais pastagem cultivada; 3 = pastagem cultiva mais pastagem natural; SAVk = efeito do sistema de acasalamento que originou as vacas de ordem "l", sendo 1 = puras e $2=$ mestiças F1; GGVl (SAV) $k=$ efeito do grupo genético da vaca de ordem " $\mathrm{m}$ " sendo $1=$ Charolês $(\mathrm{C}) ; 2=$ Nelore $(\mathrm{N}) ; 3=1 / 2 \mathrm{CN}$ e $4=1 / 2 \mathrm{NC}$ dentro do sistema de acasalamento de ordem "k"; (PAST*GGV[SAV])jkl = interação entre j-ésimo sistema de alimentação e k-ésimo grupo genético da vaca dentro do k-ésimo sistema de acasalamento;
$(\mathrm{PAST} * \mathrm{SAV}) j k=$ interação entre j-ésimo sistema de alimentação e k-ésimo sistema de acasalamento; $\varepsilon i j k l=$ erro aleatório residual, $\operatorname{NID}(0, \sigma 2)$. Adotouse 5\% de significância máxima.

As médias foram comparadas pelo teste " $t$ ". As variáveis reprodutivas percentagens de prenhez, natalidade e desmame dentro dos diferentes grupos genéticos e sistemas alimentares foram analisadas pelo teste de Qui-quadrado ao nível de significância de $5 \%$.

\section{Resultados e Discussão}

Não houve interação significativa para as variáveis estudadas entre os sistemas alimentares e os grupos genéticos, desta forma, os resultados são apresentados e discutidos separadamente para esses efeitos.

As vacas mantidas em pastagens cultivadas (PC) no período pós-parto embora praticamente mantendo o seu peso corporal durante a lactação $(0,020 \mathrm{~kg} / \mathrm{dia})$, produziram mais quilos de bezerros ao desmame. Isso demonstra o quanto é desgastante a lactação para a vaca, pois embora em melhores 
condições alimentares, em pastagem cultivada, a qual the possibilitaria maiores ganhos de pesos (MOOJEN; RESTLE; MOOJEN, 1994; LOBATO et al., 1998) mantiveram os seus pesos corporais em função da produção de leite, melhorando a alimentação dos bezerros e consequentemente, favorecendo seu peso.

Considerando os valores de parição no ano subsequente $(43,8 \%)$ das vacas mantidas exclusivamente em pastagem nativa (PN) (Tabela 1) são necessárias 2,29 vacas para o nascimento de um bezerro (Tabela 2), demonstrando a ineficiência do processo de cria de forma extensiva em PN. Para o processo de cria ser considerado eficiente é necessário que cada vaca desmame um bezerro por ano (TORRES JUNIOR et al., 2009), pois o custo de manutenção de animais improdutivos é muito oneroso ao sistema. A manutenção destes percentuais de vacas falhadas em rebanhos comerciais é determinante da menor produtividade e rentabilidade de sistemas de ciclo completo
(BERETTA; LOBATO; MIELITZ NETO, 2002), em função da não diluição dos custos fixos como o custo da terra, a mão de obra e insumos utilizados pelas vacas que não conceberam (PÖTTER; LOBATO; MIELITZ NETO, 2000).

Ao avaliar a eficiência das vacas em $\mathrm{kg}$ de bezerros para cada $100 \mathrm{~kg}$ de unidade de tamanho metabólico das vacas, ou ainda ajustado para a taxa de parição subsequente (Tabela 2) verifica-se similaridade entre os três grupos, não possuindo as sequencias alimentares compostas de pastagens nativa e cultivadas, influência sobre estes índices $(\mathrm{P}>0,05)$. Este fato se deve em parte ao maior desgaste das reservas corporais das vacas mantidas exclusivamente em pastagens naturais recorrendo as mesmas às suas reservas corporais para manter a lactação. Estes menores pesos das vacas, em função dos desgastes para a manutenção da produção de leite, refletida no desenvolvimento dos bezerros proporcionam uma eficiência similar entre as diferentes sequencias alimentares.

Tabela 2. Ganho de peso de vacas e bezerros desde o nascimento até o desmame, produtividade e eficiência dos sistemas alimentares segundo as sequencias de alimentação pré e pós-parto.

\begin{tabular}{|c|c|c|c|}
\hline Características & $\mathrm{PN}$ & $\mathrm{PC}+\mathrm{PN}$ & $\mathrm{PN}+\mathrm{PC}$ \\
\hline Ganho de peso das vacas do parto ao desmame, $\mathrm{kg}$ & $-20,0 \pm 2,3^{b}$ & $-29,0 \pm 2,5^{b}$ & $0,02 \pm 2,5^{\mathrm{a}}$ \\
\hline Vacas para produzir 1 bezerro, $\mathrm{n}$ & 2,29 & 1,55 & 1,82 \\
\hline Índice de produção de bezerros, $\mathrm{kg} / \mathrm{vaca}^{1}$ & $37,7 \pm 1,60^{\mathrm{c}}$ & $59,7 \pm 1,56^{\mathrm{a}}$ & $54,1 \pm 1,60^{\mathrm{b}}$ \\
\hline Eficiência rebanho, $\mathrm{kg}$ bezerros $/ 100 \mathrm{~kg}$ vaca & $22,3 \pm 2,7^{\mathrm{b}}$ & $22,5 \pm 2,7^{b}$ & $24,1 \pm 2,9^{\mathrm{a}}$ \\
\hline $\mathrm{Kg}$ de bezerros produzidos/vaca exposta & $53 \pm 3,1^{\mathrm{b}}$ & $61 \pm 3,0^{\mathrm{a}}$ & $69 \pm 3,4^{\mathrm{a}}$ \\
\hline $\mathrm{Kg}$ bezerro desmamado/peso vaca ${ }^{0,75}, \mathrm{~kg}^{2}$ & $22,23 \pm 0,75$ & $22,88 \pm 0,73$ & $23,52 \pm 0,74$ \\
\hline Kg bezerro desmamado/peso vaca ${ }^{0,75}, \mathrm{~kg}^{3}$ & $0,983 \pm 0,03$ & $1,035 \pm 0,03$ & $1,071 \pm 0,03$ \\
\hline
\end{tabular}

$\mathrm{PN}$ - Pastagem natural no pré e pós-parto; $\mathrm{PC}+\mathrm{PN}$ - Pastagem cultivada no pré e natural no pós-parto; $\mathrm{PN}+\mathrm{PC}-\mathrm{Pastagem} \mathrm{natural}$ no pré e cultivada no pós-parto.

a, b, c Médias seguidas por letras minúsculas diferentes na linha, diferem $(\mathrm{P}<0,05)$ pelo teste $\mathrm{F}$.

${ }^{1}$ Peso bezerro ao desmame $\mathrm{x}$ taxa de parição/100 = kg de bezerro desmamado/vaca mantida (VAZ; LOBATO; RESTLE, 2010).

${ }^{2}$ Peso bezerro ao desmame/peso metabólico da vaca ao desmame*100 (VAZ; LOBATO; RESTLE, 2010).

${ }^{3}$ Peso bezerro ao desmame ajustado para taxas de parição/peso metabólico da vaca ao desmame*100 (VAZ; LOBATO; RESTLE, 2010).

Maiores quantidades de $\mathrm{kg}$ de bezerros para cada $100 \mathrm{~kg}$ de vaca são relatados por Ribeiro et al. (2001) ao trabalharem com vacas de cria em diferentes manejos alimentares através da utilização de pastagens cultivadas, onde vacas mantidas em melhores condições de alimentação produziram 
maiores quantidades expressas em $\mathrm{kg}$ de bezerros, com valores de $165 \mathrm{~kg}$ de bezerros desmamados para cada $100 \mathrm{~kg}$ de vaca ${ }^{0,75}$, porém com desmame aos 182 dias de idade. O melhor nível nutricional em vacas em lactação é fator determinante de melhores resultados de eficiência biológica por ocasião do desmame (RESTLE et al., 2007).

As intensificações dos sistemas produtivos, visando aumentos da produtividade animal através da utilização de pastagens ou de qualquer tecnologia devem ser avaliadas de forma sistêmica, pois todas estas tecnologias envolvem maiores desembolsos e muitas causam reflexos indiretos no sistema, os quais muitas vezes não são levados em consideração na adoção ou não destas tecnologias. São necessários cuidados na interpretação analisando a metodologia de resultados experimentais quando estes envolvam produtividade e eficiência de raças e sistemas de produção de gado de cria (BARCELLOS; LOBATO; FRIES, 1996; OAIGEN et al., 2009).

Nos sistemas alimentares a utilização de pastagens cultivadas no pré-parto, não aumentou o ganho de peso das vacas, em relação às vacas mantidas exclusivamente em pastagens naturais, porém vacas submetidas a pastagens cultivadas no período pós-parto mantiveram seu peso corporal até o desmame aos 90 dias, com pequenos ganhos de $0,020 \mathrm{~kg} / \mathrm{dia}$, o que pode ser fundamental na repetição de prenhez das vacas ou mesmo na aceleração da sua terminação em caso de descarte por infertilidade após o desmame dos bezerros. Ribeiro, Restle e Pires (1990) observaram baixos desempenhos reprodutivos em vacas primíparas, mesmo quando as mesmas tiveram acesso a pastagens cultivadas no pré-parto, e posteriormente no pós-parto devido à redução no nível alimentar associada a fatores climáticos, as mesmas tiveram perdas de pesos coincidindo com o período reprodutivo subsequente. Isto demonstra a importância da manutenção do peso e da condição corporal no período pós-parto.

As chances de concepção em bovinos de corte aumentam consideravelmente a partir do momento que as vacas não perdem peso, sendo que para cada $0,1 \mathrm{~kg} \mathrm{dia}^{-1}$ de variação corporal diária positiva durante o período de acasalamento eleva em 17,9\%, a taxa de concepção em vacas Nelore x Hereford em ambiente subtropical (GRECELLÉ et al., 2006), e de $7,47 \%$ em vacas Nelore no Pantanal no Mato Grosso do Sul (BATISTA et al., 2012).

Ocorreu similaridade na produtividade do rebanho, sendo esta manifestada através do ganho de peso dos bezerros do nascimento ao desmame, para animais que tiveram acesso a pastagem cultivada no pré ou pós-desmame (61 e $69 \mathrm{~kg}$, respectivamente), sendo estes superiores $(\mathrm{P}<0,05)$ aos ganhos de peso dos bezerros mantidos com suas mães exclusivamente em pastagens naturais (53 $\mathrm{kg}$ ). Associado a este fato, ocorreu maior desgaste das vacas mantidas após o parto, em pastagens naturais, tendo as mesmas que recorrer as suas reservas corporais para a manutenção da lactação, ocasionando variações de pesos corporais negativas do parto até o desmame aos 90 dias sendo, de -20,0 e $-29,0 \mathrm{~kg}$, para vacas mantidas exclusivamente em pastagens naturais e vacas mantidas no préparto em pastagens cultivadas, respectivamente. $\mathrm{O}$ peso corporal e a variação do mesmo em vacas de corte estão correlacionados com as suas reservas corporais, as quais estão relacionadas com a produção de leite das mesmas e consequentemente, o desempenho dos bezerros (VIEIRA et al., 2005b).

Desta forma, o desempenho dos bezerros foi proporcional aos ganhos de pesos e acúmulos de reservas registrados pelas vacas durante as fases pré e pós-parto, onde vacas em melhores condições alimentares que mantiveram peso ou ainda que armazenaram reservas corporais com alimentação melhorada no pré-parto, produziram mais $\mathrm{kg}$ de bezerros do que vacas mantidas exclusivamente em pastagens naturais, com perdas de pesos nos períodos pré e pós-parto. Em vacas leiteiras mestiças, o aumento do nível alimentar via suplementação no período pré-parto melhora o escore corporal mas não a produção de leite das vacas, e o aumento do nível alimentar via suplementação nos período pós-parto 
melhoram tanto o escore corporal quanto a produção de leite (SALMAZO et al., 2012), devendo isso se manifestar em maior eficiência produtiva em $\mathrm{kg}$ de bezerros e desempenho reprodutivo das vacas.

Em sistemas de cria, a produção de quilos de bezerros, o peso corporal da vaca e a relação entre estes dois são maneiras adequadas de medir a produtividade e eficiência individual ou em nível de rebanho (BARCELLOS; LOBATO; FRIES, 1996; RIBEIRO et al., 2001). Em ganho de peso corporal desde o nascimento até o desmame os conjuntos vaca + bezerro produziram 33,0,32,0 e 69,0 kg em sistemas de vacas mantidas com cria ao pé em pastagens naturais, pastagens cultivadas e naturais e pastagens naturais e cultivadas no pré e pós-parto, respectivamente. Euclides Filho, Figueiredo e Euclides (1995) ao trabalharem com vacas mestiças de maiores tamanhos, Nelore com Chianina, Charolês e Fleckvieh observaram valores mais elevados ao do presente estudo. Porém, Ribeiro et al. (2001) mostraram serem as vacas menores, as que apresentam melhor eficiência produtiva, porém, com pesos dos bezerros ajustados para 205 dias.

Ao analisar os resultados referentes aos índices de produção de bezerros (Tabela 2) verifica-se que a média das vacas submetidas à pastagem cultivada independente do período produzem $50,9 \%$ mais $\mathrm{kg}$ de bezerros na estação de parição subsequente em comparação com as vacas mantidas exclusivamente em pastagens naturais.

Foram obtidos valores de 59,7, 54,1 e $37,7 \mathrm{~kg}$ de bezerros desmamados na estação de parição subsequente por vaca mantida no rebanho $(\mathrm{P}<0,05)$ em sistemas com pastagem cultivada no pré-parto, no pós-parto e exclusivamente em pastagem natural, respectivamente. $\mathrm{O}$ melhor desempenho das vacas mantidas em pastagem cultivada no pré-parto se deve provavelmente à associação com a melhora das pastagens naturais no período pós-parto, onde a qualidade, mas principalmente o crescimento determinam maior oferta e disponibilidade aos animais das mesmas.
Estes resultados mostram ser a pastagem cultivada uma ferramenta eficiente na produção de $\mathrm{kg}$ de bezerros na estação de parição/desmame por vaca mantida no rebanho. De acordo com os resultados obtidos, o desempenho reprodutivo não pode ser analisado somente em função da manifestação de estros e da percentagem de parição, pois os mesmos não são sinônimos de maiores produções de $\mathrm{kg}$ de bezerros por hectare. A intensificação de sistemas produtivos através de tecnologias de produção implantadas devem suprir as necessidades dos mesmos e a avaliação destas devem originar melhores condições de tomada de decisão da sua utilização ou não nos variados sistemas produtivos de ruminantes (BARCELLOS et al., 2011), devendo as mesmas serem avaliadas de forma sistêmica e não pontual, vendo todos os efeitos diretos e indiretos das tecnologias (OAIGEN et al., 2009).

Desta forma, devido às diversas perdas desde a manifestação de cios até o desmame dos bezerros, os resultados são determinantes de desempenhos reprodutivos incompatíveis com pecuárias de corte produtiva e eficiente. A taxa de desmame associada ao peso dos bezerros é a maneira mais correta de se avaliar um rebanho de cria. Beretta, Lobato e Mielitz Neto (2001) ao trabalharem com taxas de natalidade de 82,5 e $92,5 \%$, encontraram produções de bezerros de 83,9 e 77,9 kg/ha, respectivamente.

De acordo com os resultados, para uma mesma produção de $\mathrm{kg}$ de bezerros entre as sequencias de alimentação, é necessário $50,9 \%$ a mais de vacas no rebanho de cria. Este fato pode acarretar no sistema produtivo diminuição de áreas destinadas às categorias mais jovens com consequente aumento da ineficiência produtiva. Baixas taxas de desmame afetam o desfrute dos sistemas produtivos, sendo os mesmos penalizados pela baixa venda de animais quando mantido o estoque animal. Desta forma, Perotto et al. (2006) revelam a necessidade de se melhorar as práticas de manejo, principalmente os nutricionais, visando a melhora na eficiência reprodutiva. 
Melhores resultados em taxas de desfrute e de eficiência produtiva dos rebanhos de cria, os quais melhoram os indicadores de produtividade, são verificados em sistemas com altos índices reprodutivos e menores idades do primeiro acasalamento das novilhas e de abate dos novilhos (PÖTTER; LOBATO; MIELITZ NETO, 2000; BERETTA; LOBATO; MIELITZ NETO, 2002), diminuindo a improdutividade em rebanhos de cria onde as vacas devem produzir um bezerro/ ano, com eliminação das improdutivas do rebanho, aumentando o retorno econômico (VAZ; ROSO; VAZ, 2000).

Com os valores de parição subsequente de $33,3 \%$, são necessárias 3,0 vacas para o nascimento de um bezerro no ano subsequente, no grupo genético das Nelores (Tabela 3), demonstrando a fragilidade do mesmo quando em condições adversas de meio ambiente e nutrição associados às altas exigências alimentares, não sendo as mesmas supridas pela alimentação disponibilizada, diferindo dos demais grupos genéticos $(\mathrm{P}<0,05)$. Mesmo em condições climáticas melhores, ao trabalharem com vacas Nelores no Pantanal, Batista et al. (2012), verificaram ter o ganho de peso, relação direta com a prenhez das vacas, onde animais que perderam até $0,48 \mathrm{~kg} /$ dia tiveram probabilidade de prenhez de $7,48 \%$, enquanto que animais ganhando $0,72 \mathrm{~kg} /$ dia obtiveram probabilidade de $83,7 \%$, mostrando que os animais que estão em variação positiva de ganho de peso corporal aumentam a sua probabilidade de prenhez.

Verificou-se também que nos demais grupos genéticos, a eficiência do processo de cria esteve abaixo do desejado, necessitando de 1,74, 1,34 e 1,58 vacas para a produção de um bezerro no ano subsequente para vacas Charolês, $1 / 2 \mathrm{CN}$ e $1 / 2 \mathrm{NC}$, respectivamente, o que torna o sistema de cria ineficiente e improdutivo (PÖTTER; LOBATO; MIELITZ NETO, 2000; BERETTA; LOBATO; MIELITZ NETO, 2002).

$\mathrm{O}$ grupo genético influenciou $(\mathrm{P}<0,01)$ o ganho dos bezerros $(\mathrm{kg})$ até o desmame, apresentando menor produção os bezerros filhos de vacas Nelores, sendo que os demais grupos não apresentaram diferença entre si. Entre os animais puros, a maior produção de $\mathrm{kg}$ de bezerros até o desmame dos animais Charolês em relação aos animais Nelore se deve ao efeito da menor adaptação das vacas Nelore as condições do RS, mostrando maior sensibilidade refletida na produção de leite e consequente desempenho dos seus bezerros. Restle et al. (2007) verificaram pesos mais elevados ao desmame e maior ganho de peso de bezerros Charolês, $1 / 2 \mathrm{CN}$ e $1 / 2 \mathrm{NC}$, quando comparado ao de animais Nelore.

Independente do grupo genético das vacas, do parto até o desmame todos tiveram perdas de peso corporal, sendo que as vacas $1 / 2 \mathrm{NC}$ foram as que mais perderam peso não havendo diferença entre as demais $(\mathrm{P}<0,05)$. $\mathrm{O}$ controle do peso corporal de vacas de corte é uma alternativa para controlar perdas de eficiência reprodutiva (BATISTA et al., 2012). A maior perda de peso das vacas $1 / 2 \mathrm{NC}$ em partes se deve ao maior tamanho corporal destas fêmeas, o que ocasiona uma maior exigência nutricional de mantença, a qual não conseguiu ser suprida pela alimentação fornecida, associada à lactação no período pós-parto. Este fato pode ser associado à produção de bezerros em relação ao tamanho metabólico da vaca. Novamente verifica-se uma inferioridade dos demais grupos $(\mathrm{P}<0,05)$ em relação às vacas $1 / 2 \mathrm{NC}$, de forma que a maior produção de quilos de bezerros teve como consequência, a maior perda de peso destas vacas durante a lactação para manter a produção de leite e aumentar o peso de bezerros produzido por vaca.

Ao analisar os resultados referentes aos índices de produção de bezerros (Tabela 3 ) verifica-se serem as vacas Nelores menos produtivas com $42,3 \mathrm{~kg}$ de bezerros na estação de parição subsequente para cada vaca mantida no rebanho, quando comparadas com vacas Charolesas, $1 / 2 \mathrm{CN}$ e $1 / 2 \mathrm{NC}$ com valores de 49,9, 55,2 e 54,6 kg de bezerros, respectivamente. Este fato também ocorreu quando se avaliou a 
produtividade dos rebanhos expressa em quilos de bezerros produzidos por vaca. Mesmo com valores mais baixos em relação aos demais grupos nas características de produtividade e eficiência dos rebanhos, as vacas Nelores, demonstram que a variabilidade entre os indivíduos do mesmo grupo genético é muito grande, podendo esta ser maior do que a variabilidade entre os grupos genéticos, pois existem indivíduos que mesmo em condições adversas conseguem ter maior produção em relação aos demais. A herdabilidade de características reprodutivas mostra existirem variabilidades genéticas e a possibilidade de seleção para esta característica (PEROTTO et al., 2006).

Tabela 3. Ganhos de pesos de vacas e bezerros do nascimento ao desmame, produtividade e eficiência de rebanhos de vacas de acordo com os grupos genéticos e sistema de acasalamento.

\begin{tabular}{|c|c|c|c|c|c|c|}
\hline & \multicolumn{2}{|c|}{ Pesos (kg) } & \multicolumn{3}{|c|}{ Índices (kg) } & \multirow[b]{2}{*}{$\begin{array}{c}\text { Vacas/ } \\
\text { bezerro } \\
\text { produzido }\end{array}$} \\
\hline & $\begin{array}{c}\text { Vacas } \\
\text { Parto ao } \\
\text { desmame }\end{array}$ & $\begin{array}{c}\text { Bezerro/peso } \\
\text { Metabólico } \\
\text { Vaca }^{1}\end{array}$ & $\begin{array}{c}\text { Produção } \\
\text { bezerros, kg/ } \\
\text { vaca }^{2}\end{array}$ & $\begin{array}{c}\text { Produtividade, } \\
\text { bezerro / } \\
\text { vaca }^{2}\end{array}$ & $\begin{array}{c}\text { Eficiência, } \\
\text { bezerros/ } \\
100 \text { kg vaca }\end{array}$ & \\
\hline Charolês & $-17,0 \pm 2^{b}$ & $0,997 \pm 0,03^{\mathrm{ab}}$ & $49,9 \pm 1,51^{\mathrm{ab}}$ & $64,2 \pm 3,7^{a}$ & $15,3 \pm 2,1$ & $1,72^{\mathrm{a}}$ \\
\hline Nelore & $-17,0 \pm 2^{b}$ & $0,961 \pm 0,03^{\mathrm{b}}$ & $42,3 \pm 1,63^{b}$ & $54,0 \pm 3,2^{\mathrm{b}}$ & $14,9 \pm 2,0$ & $3,00^{\mathrm{b}}$ \\
\hline Média Puras & $-17,0 \pm 2$ & $0,979 \pm 0,02^{\mathrm{B}}$ & $46,9 \pm 1,12^{\mathrm{B}}$ & $59,1 \pm 3,3^{\mathrm{B}}$ & $15,1 \pm 2,1$ & $2,36^{\mathrm{B}}$ \\
\hline $1 / 2 \mathrm{CN}$ & $-7,0 \pm 2^{\mathrm{a}}$ & $1,075 \pm 0,04^{\mathrm{ab}}$ & $55,2 \pm 2,34^{\mathrm{a}}$ & $61,8 \pm 3,9^{\mathrm{a}}$ & $14,1 \pm 2,0$ & $1,43^{\mathrm{a}}$ \\
\hline $1 / 2 \mathrm{NC}$ & $-24,0 \pm 4^{b}$ & $1,087 \pm 0,04^{\mathrm{a}}$ & $54,6 \pm 2,04^{\mathrm{a}}$ & $66,7 \pm 4,0^{\mathrm{a}}$ & $15,5 \pm 2,2$ & $1,63^{\mathrm{a}}$ \\
\hline Média F1 & $-14,0 \pm 2$ & $1,081 \pm 0,03^{\mathrm{A}}$ & $54,9 \pm 1,63^{\mathrm{A}}$ & $64,3 \pm 3,7^{\mathrm{A}}$ & $14,8 \pm 2,0$ & $1,53^{\mathrm{A}}$ \\
\hline Heterose, $\%$ & $-17,6$ & 0,56 & 17,1 & 8,8 & $-2,0$ & $-35,16$ \\
\hline
\end{tabular}

Pesos dos bezerros (SENNA, 1996).

a, b Médias seguidas por letras minúsculas diferentes na linha, diferem $(\mathrm{P}<0,05)$ pelo teste $\mathrm{F}$.

${ }^{1}$ Peso bezerro ao desmame ajustado para taxas de parição/peso metabólico da vaca ao desmame*100 (VAZ; LOBATO; RESTLE, 2010).

${ }^{2}$ Peso bezerro ao desmame $\mathrm{x}$ taxa de parição/100 $=\mathrm{kg}$ de bezerro desmamado/vaca mantida (VAZ; LOBATO; RESTLE, 2010).

Foram observados valores de heteroses significativas para a maioria das variáveis estudadas, tanto de desenvolvimento animal, como de desempenho reprodutivo, sendo estas muitas vezes negativas, mas com reflexos positivos na produção dos sistemas, demonstrando a superioridade dos animais cruzados em relação aos definidos, consolidando a utilização de cruzamentos para o aumento da produtividade dos rebanhos.

\section{Conclusões}

A produção de $\mathrm{kg}$ de bezerros/vaca é maior em sistemas alimentares com a utilização de pastagens cultivadas no pré ou pós parto, bem como a produção em kg de vacas até o desmame é superior em animais mantidos em pastagens cultivadas no pós-parto. Vacas mantidas em pastagens cultivadas no pré-parto determinam maior produção em $\mathrm{kg}$ de bezerros/vaca mantida no rebanho no ano subsequente do que vacas mantidas em pastagem no pósparto e de vacas mantidas exclusivamente em pastagens naturais.

Maior produtividade em $\mathrm{kg}$ de bezerros/vaca e de eficiência em $\mathrm{kg}$ de bezerros desmamados/ vaca acasalada na temporada de monta anterior é observada em sistemas alimentares mantidos em pastagens cultivadas no período pós-parto com a não manutenção de vacas improdutivas no rebanho.

Em fêmeas puras vacas Charolesas são mais produtoras de $\mathrm{kg}$ de bezerros, bem como mais 
eficientes na produtividade de bezerros/vaca expresso em $\mathrm{kg}$ quando comparadas com vacas Nelores.

Vacas F1 são superiores às definidas na produção de bezerros em relação ao tamanho metabólico, bem como na produção de $\mathrm{kg}$ de bezerros/vaca na estação de monta subsequente.

\section{Referências}

BARCELlOS, J. O. J.; LOBATO, J. F. P.; FRIES, L. A. Eficiência de vacas primíparas Hereford e cruzas Hereford-Nelore acasaladas no outono/inverno ou na primavera/verão. Revista Brasileira de Zootecnia, Viçosa, v. 25, n. 3, p. 414-427, 1996.

BARCELLOS, J. O. J.; QUEIROZ FILHO, L. A.; CEOLIN, A. C.; GIANEZINI, M.; MCMANUS, C.; MALAFAIA, G. C.; OAIGEN, R. P. Technological innovation and entrepreneurship in animal production. Revista Brasileira de Zootecnia, Viçosa, v. 40, n. 1, p. 189-200, 2011. Suplemento Especial.

BATISTA, D. S. N.; ABREU, U. G. P.; FERAZ FILHO, P. B.; ROSA, A. N. Índices reprodutivos do rebanho Nelore da fazenda Nhumirim, Pantanal da Nhecolândia. Acta Scientiarum Animal Science, Maringá, v. 34, n. 1, p. 71-76, 2012.

BERETTA, V.; LOBATO, J. F. P.; MIELITZ NETO, C. G. A. Produtividade e eficiência biológica de sistemas pecuários de cria diferindo na idade das novilhas ao primeiro parto e na taxa de natalidade do rebanho no Rio Grande do Sul. Revista Brasileira de Zootecnia, Viçosa, v. 30, n. 4, p. 1278-1286, 2001.

Produtividade e eficiência biológica de sistemas de produção de gado de corte de ciclo completo no Rio Grande do Sul. Revista Brasileira de Zootecnia, Viçosa, v. 31, n. 2, p. 991-1001, 2002. Suplemento.

CERDÓTES, L.; RESTLE, J.; BRONDANI, I. L.; OSMARI, E. K.; SOCCAL, D. C.; FERNANDES, M. $\mathrm{S}$. Desempenho produtivo de vacas de quatro grupos genéticos submetidas a diferentes manejos alimentares, desmamadas aos 42 ou 63 dias de idade. Revista Brasileira de Zootecnia, Viçosa, v. 33, n. 3, p. 585-596, 2004.

EUCLIDES FILHO, K.; FIGUEIREDO, G. R.; EUCLIDES, V. P. B. Eficiência de produção de vacas de corte com diferentes potenciais para a produção de leite. Pesquisa Agropecuária Brasileira, Brasília, v. 30, n. 7, p. 1003-1007, 1995.
FAGUNDES, J. I. B.; LOBATO, J. F. P.; SCHENKEL, F. $\mathrm{S}$. Efeito de duas cargas animais em campo nativo e de duas idades a desmama no desempenho de vacas de corte primíparas. Revista Brasileira de Zootecnia, Viçosa, v. 32, n. 6, p. 1722-1731, 2003. Suplemento 1.

GRECELLÉ, R. A.; BARCELLOS, J. O. J.; BRACINI NETO, J.; COSTA, E. C.; PRATES, E. R. Taxa de prenhez de vacas Nelore $\mathrm{x}$ Hereford em ambiente subtropical sob restrição alimentar. Revista Brasileira de Zootecnia, Viçosa, v. 35, n. 4, p. 1723-1430, 2006.

LOBATO, J. F. P.; DERESZ, F.; LEBOUTE, E. M.; PEREIRA, O. A. Pastagens melhoradas e suplementação alimentar no comportamento reprodutivo de vacas de corte primíparas. Revista Brasileira de Zootecnia, Viçosa, v. 27, n. 1, p. 47-53, 1998.

MOOJEN, J. G.; RESTLE, J.; MOOJEN, E. L. Efeito da época de desmama e da pastagem no desempenho de vacas e terneiros de corte. 1. Desempenho das vacas. Ciência Rural, Santa Maria, v. 24, n. 2, p. 393-397, 1994.

MOREnO, J. A. Clima do Rio Grande do Sul. Porto Alegre: Secretaria da Agricultura, 1961. $41 \mathrm{p}$.

MULLER, M.; PRADO, I. N.; ZEOULA, L. M.; PEROTTO, D.; MOLETTA, J. L.; SILVA, R. R. Flushing em vacas de corte no pós-parto, submetidas ao desmame precoce: desempenho reprodutivo. Archivos de Zootecnia, Cordóba, v. 59, n. 1, p. 131-139, 2010.

NATIONAL RESEARCH COUNCIL - NRC. Nutrient requeriment of beef cattle. Washington D.C.: National Academy Press, 1996. 244 p.

OAIGEN, R. P.; BARCELLOS, J. O. J.; CHRISTOFARI, L. F.; BRACCINI NETO, J.; OLIVEIRA, T. E.; PRATES, E. R. Análise da sensibilidade da metodologia dos centros de custos mediante a introdução de tecnologias em um sistema de produção de cria. Revista Brasileira de Zootecnia, Viçosa, v. 38, n. 6, p. 1155-1162, 2009.

PEROTTO, D.; MIYAGI, A. P.; SOUZA, J. C.; MOLETTA, J. L.; FREITAS, J. A. Estudos de características reprodutivas de animais da raça Canchim, criados a pasto, no Estado do Paraná. Archives of Veterinary Science, Curitiba, v. 11, n. 2, p. 1-6, 2006.

PÖTTER, L.; LOBATO, J. F. P.; MIELITZ NETO, C. G. A. Análises econômicas de modelos de produção com novilhas de corte primíparas aos dois, três ou quatro anos de idade. Revista Brasileira de Zootecnia, Viçosa, v. 29, n. 3, p. 861-870, 2000.

RESTlE, J.; HARGROVE, D. D.; KOGER, M. Cow performance in upgrading and rotational crossbreeding systems. Journal of Animal Science, Champaign, v. 59, n. 1, p. 45-46, 1984. 
RESTLE, J.; PACHECO, P. S.; FREITAS, A. K.; BRONDANI, I. L.; PÁDUA, J. T.; FERNANDES, J. J. R.; ALVES FILHO, D. C. Influência das taxas de ganho de peso pré-desmame das vacas e do tipo de pastagem no período pós-parto sobre a eficiência biológica de vacas e de bezerros de corte. Revista Brasileira de Zootecnia, Viçosa, v. 36, n. 4, p. 874-880, 2007.

RESTLE, J.; VAZ, R. Z.; ALVES FILHO, D. C.; BERNARDES, R. A. C.; PASCOAL, L. L.; SENNA, D. B.; POLLI, V. A. Desempenho de vacas Charolês e Nelore desterneiradas aos três ou sete meses. Revista Brasileira de Zootecnia, Viçosa, v. 30, n. 2, p. 499-507, 2001.

RIBEIRO, E. L. A.; RESTlE, J.; PIRES, C. C. Influência de diferentes sequencias de pastagens no peso e desempenho reprodutivo de vacas de corte, de dois grupos genéticos, com primeira cria ao pé. Semina: Ciências Agrárias, Londrina, v. 11, n. 1, p. 24-32, 1990.

RIBEIRO, E. L. A.; RESTLE, J.; ROCHA, M. A.; MIZUBUTI, I. Y.; SILVA, L. D. F. Eficiência produtiva em vacas primíparas das raças Aberdeen Angus e Charolês. Revista Brasileira de Zootecnia, Viçosa, v. 30, n. 1, p. 125-132, 2001.

ROVIRA, J. M. Reproducción y manejo de los rodeos de cria. Montivideo: Hemisfério Sur, 1974. 293 p.

SALMAZO, R.; MIZUBUTI, I. Y.; RIBEIRO, E. L. A.; PEREIRA, E. S.; MOREIRA, F. B.; ROCHA, M. A.; SENEDA, M. M.; HIROKI, P. T.; KRAWULSKI, C. C. Efeito de diferentes níveis de concentrado no período pré e pós-parto sobre a produção de leite e escore corporal de vacas leiteiras. Semina: Ciências Agrárias, Londrina, v. 33, n. 3, p. 1219-1224, 2012.
SENNA, D. B. Desempenho reprodutivo e produção de leite de vacas de quatro grupos genéticos desterneiradas precocemente, submetidas à diferentes períodos de pastagem cultivada. 1996. Dissertação (Mestrado em Zootecnia) - Universidade Federal de Santa Maria, Santa Maria.

TORRES JUNIOR, J. R. S.; MELLO, W. O.; ELIAS, A. K. S.; RODRIGUES, L. S.; PENTEADO, L.; BARUSELLI, P. S. Considerações técnicas e econômicas sobre reprodução assistida em gado de corte. Revista Brasileira de Reprodução Animal, Belo Horizonte, v. 33, n. 1, p. 53-58, 2009.

VAZ, F. N.; ROSO, C.; VAZ, R. Z. Aplicação gerenciamento de tecnologias na pecuária de corte moderna In: RESTLE, J. (Ed.). Eficiência na produção de bovinos de corte. Santa Maria: Editora da UFSM, 2000. p. 333-368.

VAZ, R. Z.; LOBATO, J. F. P.; RESTLE, J. Productivity and efficiency of cow herds submitted to two weaning ages. Revista Brasileira de Zootecnia, Viçosa, v. 39, n. 8, p. 1849-1856, 2010.

VIEIRA, A.; LOBATO, J.F. P.; CORREA, E. S.; TORRES JUNIOR, R. A. A.; CEZAR, I. M. Produtividade e eficiência de vacas Nelore em pastagem de Brachiaria decumbens Stapf nos cerrados do Brasil Central. Revista Brasileira de Zootecnia, Viçosa, v. 34, n. 4, p. 13571365, 2005a.

VIEIRA, A.; LOBATO, J. F. P.; TORRES JUNIOR, R. A. A.; CEZAR, I. M.; CORREA, E. S. Fatores determinantes do desempenho reprodutivo de vacas Nelore na região dos cerrados do Brasil Central. Revista Brasileira de Zootecnia, Viçosa, v. 34, n. 6, p. 2408-2416, 2005 b. Suplemento. 
